\title{
Gender Stereotyping and Inequality Behind the Slogans: A Case Study in Chinese Tertiary Education
}

\section{Yi Yang}

https://orcid.org/0000-0002-3019-6732

Shanghai Jiao Tong University, China

11904yang@sjtu.edu.cn

\section{Xunqian Liu}

https://orcid.org/0000-0002-2259-3746

Shanghai Jiao Tong University, China

a0103212@163.com

\author{
Zhongrun Chen \\ https://orcid.org/0000-0001-6000-081X \\ Shanghai Jiao Tong University, China \\ W87293672@outlook.com
}

\section{Abstract}

The increasing number of female students in China has contributed to reducing the gender gaps in tertiary education over the past decades; however, the debate about gender inequality in tertiary education is ongoing. This study examines how the slogans on the banners for Girls' Day celebrations from 2018-2020 on university campuses in mainland China convey male students' willingness to provide help and support for the perceived academic issues faced by female college students, while surreptitiously conveying gender stereotyping and intelligence quotient (IQ) prejudice in the current university campus culture. These slogans occupy a prominent position on campus and help to evaluate the perceptions of both male and female college students regarding these issues. Data were gathered from semi-structured interviews with 16 undergraduate students at two universities. The analysis revealed that female IQ bias based on gender stereotyping is an enduring issue, which has been unintentionally inherited from previous generations of Chinese college students. The article reveals that despite the increased number of female college students, "benevolent discrimination" against women still exists in various forms in the campus culture and gender roles have not transformed much. The findings of this study can inform future gender education, orienting its effort towards a clearly identified niche of users.

Keywords: tertiary education; Girls' Day; IQ bias; gender stereotyping; China

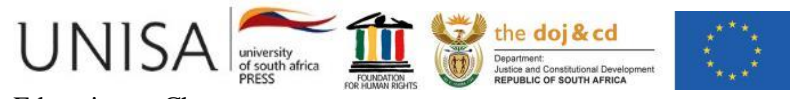




\section{Introduction}

Education is one of the key methods to achieve gender equality. The UNESCO Education 2030 agenda recognises that gender equality requires an approach that "ensures that girls and boys, women and men not only gain access to and complete education cycles, but are empowered equally in and through education" (UNESCO 2016). For the past few years, increasing attention has been given to the importance of achieving gender equality in education. There has been significant publicity about social inequalities in the attainment of higher levels of education in many countries (Breen et al. 2009). In China, with rapid economic development, there has been a very substantial increase in female enrolment. Data from the National Bureau of Statistics show that in $2016,50.6 \%$ of postgraduate students were female, exceeding the percentage of males for the first time. In the same year, women accounted for $52.5 \%$ of college students (Xinhua News Agency 2017).

Currently, the number of women in Chinese universities has increased and the majority of students in higher education institutions are females; thus, males and females have relatively equal educational conditions and opportunities. However, the question remains whether the increased access of women to higher education also reflects a reduction of gender inequality in universities, that is, equal treatment to realise one's full potential, rights, and academic performance. This article investigates whether a new form of gender inequality exists in higher education. As a case study, the article analyses the March Seventh Girls' Day at Chinese universities. The slogans used during this gender-oriented festival provide us with a typical window to review the gender stereotyping and inequality in Chinese tertiary education.

\section{Background}

The Girls' Day festival originated at Shandong University in mainland China and was held for the first time at its Science Hall on 7 March 1986. Since then, it has gradually become popular at other Chinese universities and colleges, and has been embraced by groups of female college students as an informal festival with widespread participation. As it is an unofficial festival, there is no formal definition or explanation of March Seventh Girls' Day. According to Guangming Daily - a national Chinese-language daily newspaper published in the People's Republic of China-Girls' Day is a festival to express care for college women and to exhibit their talents (Guangming Daily 2013). Other descriptions portray it as an opportunity to display the bright youthfulness and positive style of modern female college students or as a way for female college students to promote their self-image (Tsinghua University News 2019). At many colleges and universities, Girls' Day is celebrated with banners created by the students, as well as with various activities, such as wishing walls and wishing cards. Male college students also give gifts and flowers and sing songs to female students on this special day.

Initially, Girls' Day did not feature gifts, banners, or parties; it merely comprised a lecture or a few charitable activities. In 2010, however, as a special gift in Tsinghua 
University, the male students hung the first Girls' Day banner from the Department of Mechanical Engineering to be visible opposite the girls' dormitory. This innovative practice became popular on social platforms such as Renren Network (a Chinese social networking service similar to Facebook and very popular among college students), where banners were closely linked to Girls' Day. Since 2012, photos of banners on Girls' Day have been commonly posted on social platforms, spreading from Tsinghua University to the rest of the country. In the years that followed, the profound impact of these creative festival banners attracted attention from the national media, and the red banners are now an indispensable part of the Girls' Day festival.

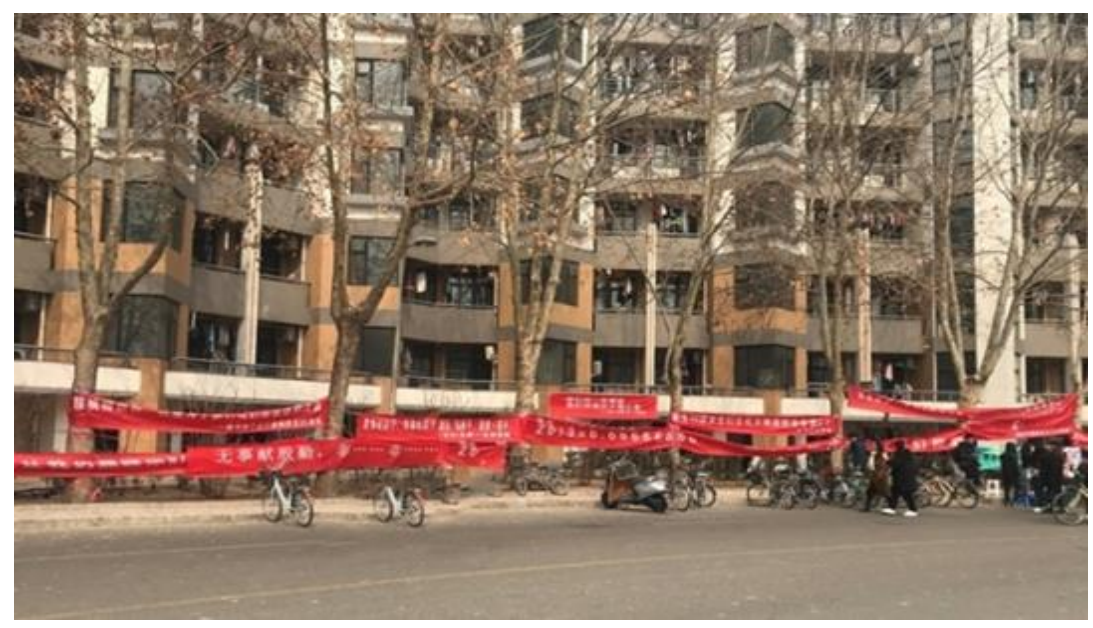

Figures 1: Red banners with kind words and loving phrases displayed on campus on 7 March 2019 at University T. (Photo by authors)

All these festival banners for college women represent a typical gender discourse created by college men with a male perspective and tone. The festival intends to express goodwill and praise for female students. Based on our collection and collation of banners from Girls' Day festivals at major colleges and universities in China between 2018-2020, the content mainly consists of male students expressing their admiration for female students, written in words of love (see Figure 1):

Flowers are no prettier than you at forever 18.

Everything tastes bitter to me, but you have a sweet flavour.

However, in addition to these "words of love", slogans that convey a willingness to provide help and support to college women for the academic problems they face are also prominent. For example:

My plaid shirts are for you. ${ }^{1}$ My code can be half yours.

You caught my attention while you were struggling with your homework.

1 Dressed in a plaid shirt and jeans like a typical Chinese programmer. 
Happiness every day, no failed exams.

Afternoon tea for you, Construction blueprint drawing for me.

Electronics boys' strengths: to connect circuits, write code, and love you.

Still, training? Enjoy a holiday with us and receive a reward.

Shall we study electromechanics together when the epidemic is over?

Willing to do the mathematical analysis work for you.

I'm not a handsome boy, but I would sincerely write code for you.

With us beside you, you will achieve all your goals.

I will accompany you with the patience of nourishing cells, and warm you with a passion for scientific research.

Put your name on every page of my research report.

The slogans quoted above were selected from our field investigation and social network platforms during the period of 2018-2020. In recent years, numerous banners with messages have been displayed in various universities on Girls' Day (Zhang 2021). Our slogans were collected from two top science and engineering universities in China. This is because the highest number of banners were displayed at these two universities ( $T$ and S). The celebration of Girls' Day has even become a regular feature on students' calendars in both universities. We collected 117 banners in total from 2018-2020. It should be explained that, due to COVID-19, students took courses online from home in the spring 2020 semester. Girls' Day on 7 March 2020 was during the campus closure period. On that day, boys in University $\mathrm{T}$ and University S made a "Cloud Banner" instead and posted their "well-wishes" on a microblogging platform (Sohu News 2020a; 2020b). Most of the characters in the original banners were in Chinese. In order to make it easier for readers to understand, we have translated the slogans into English.

As we can see, Girls' Day is a gender-oriented festival. The popularity of festival banners at colleges and universities influences student groups in several ways and is shaping a novel gender culture in mainland China. As college students are highly involved in this informal festival, Girls' Day banners have become a focal point of male students' attitudes towards females. The external manifestation of the banner contents consists of both the collectivisation of the object and the openness of the recipients; hence, the gender concept and relationship created by the banner imply that college women need male students' help to complete their academic work. 

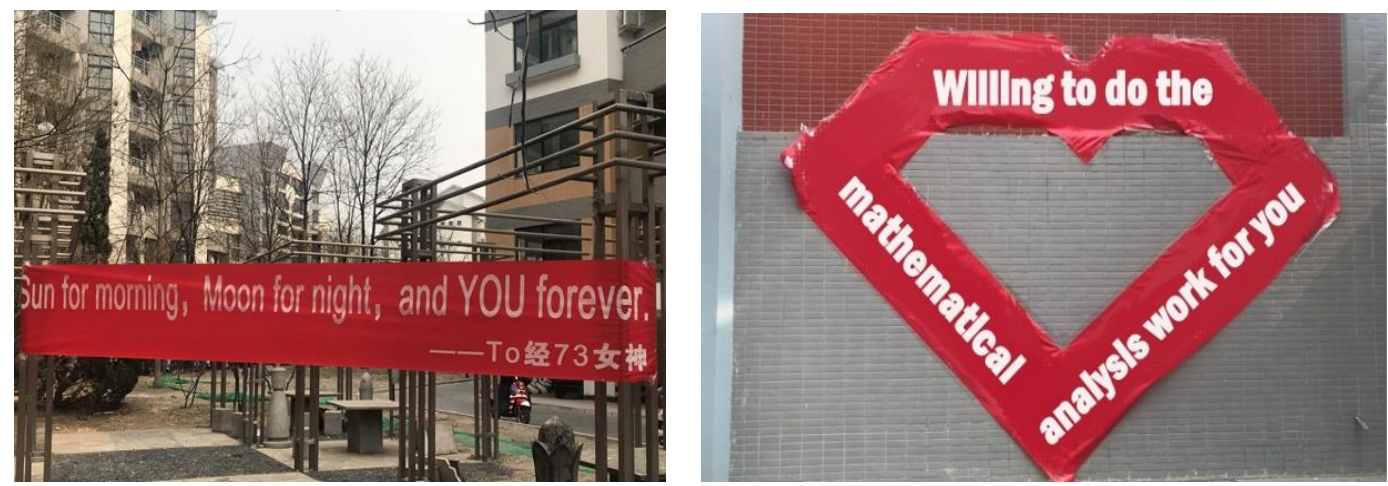

Figure 2a and 2b: The banners displayed on campus to celebrate Girls' Day at University T in Beijing, March 7, 2019. (Photo by authors)

\section{Theoretical Considerations}

Following Deary et al. (2007), we use the concept of intelligence quotient (IQ), which is generally used to measure individual differences in cognitive abilities, including planning, reasoning, comprehension, abstraction, and learning. Although both genders exhibit different strengths and weaknesses, female students are rated as having lower IQs than male students even by themselves (Forgasz, Leder, and Kloosterman 2004). Historically, STEM fields (Science, Technology, Engineering, and Mathematics), which are thought to require a high IQ, have been stereotyped as male domains.

In general, males have been found to believe that their mathematical abilities are superior to those of females. This is a gender stereotype. Gender stereotypes are socially validated general beliefs that certain activities, items, traits, and occupations are appropriate for one gender only (Rainey and Rust 1999). The seeds of gender bias in IQ discrepancy are usually planted early in life, refined at home, and experienced at school. According to Parker and Davis (1999), a gender bias, which is often subtle and difficult to detect, weakens females' self-esteem, limits their aspirations, and affects their entire careers.

The terms "gender bias" and "gender consciousness" are often discussed together. Generally, gender consciousness is an awareness of how one's gender affects many aspects of life, such as political preferences, careers and religious beliefs (Rinehart 2013). In three national cross-section sample surveys conducted over the decade of the 1970s by the Institute for Social Research, in all but one of these dimensions, women's gender consciousness was comparatively weak (Gurin 1985). A key step towards gender consciousness is to question the hidden curriculum in both individual and connected learning. In educational contexts, gender consciousness can also play a facilitating role. Researchers found that greater gender consciousness can help advance women's academic performance and future careers (Kollmayer, Schober, and Spiel 2018), which is especially relevant to our study. 
In addition, it is important to explain the notion of "girls" in this article, which is a term female students use to refer to themselves in the interviews. In Western contexts, the term "girl" generally refers to a young or relatively young woman, whereas the term "woman" applies to an adult female. Under normal contexts, "woman" and "female" are neutral terms, but "lady" and "girl" are potentially biased terms (Cralley and Ruscher 2005). However, it should be noted that the impression Chinese college students have of Women's Day is the result of the historical and cultural stereotypes that underlie the word "woman" in Chinese characters, as well as the government's actions on Women's Day in China. First, the word "woman" was translated into the Chinese word 妇女 (fù nü), which is most commonly used to refer to married women, although it can sometimes also be used to refer to all females. Except for legal documents, Chinese people seldom call unmarried young females "women" in their daily speech. In addition, being influenced by China's enduring thought regarding men's superiority over women, activities conducted by the Chinese government and labour unions on Women's Day have transformed International Women's Day, which was originally designed to encourage women to strive for their rights and interests, into a "care for women" activity. Women's Day seems to have become a festival to show care for middle-aged and older women in China, and as a result, it is not difficult to understand that before becoming "married women", young female college students refuse to regard Women's Day as their festival, and instead participate in new subcultural forms.

As observed above in the Girls' Day banners, gender stereotyping and IQ bias remain prevalent in mainland China and have become part of today's campus culture. To date, however, no study has examined the slogans on banners for Girl's Day that reveal gender stereotyping and IQ prejudice. This serves as a direct reflection of gender stereotyping and IQ bias in campus culture, encompassing the projected meaning and narrative presentation of this cultural ecology. This study considers the gender stereotyping and IQ prejudice showcased by March Seventh Girls' Day banners in mainland Chinese universities for the past three years to investigate and discuss this phenomenon within college student groups.

Focusing on a group of students whose universities have March Seventh Girls' Day activities, this study was guided by the following research questions:

1. How do students of different genders and majors perceive and respond to these slogans?

2. How do the slogans reflect the gender stereotyping and inequality in Chinese tertiary education?

3. Based on students' understanding and attitudes, what are the implications for the future of tertiary education? 


\section{Materials and Methods}

\section{Participants}

Under normal circumstances in mainland China, universities are public institutions that offer both undergraduate and postgraduate degrees, with sizable campuses and a wide variety of programme offerings. Colleges often feature smaller student populations and fewer programme offerings than universities. Undergraduate students from two large, public universities, University $\mathrm{T}$ and University $\mathrm{S}$, in China were recruited to participate in a qualitative study to examine college students' perceptions of gender stereotyping and inequality behind the slogans used on Girls' Day. Both universities are classified as "985" universities (Chinese top-tier higher education institutions that receive enhanced government funding), the most prestigious universities in China. The structure and overall arrangement of majors at both universities are characterised by science and technology subjects, such as mechanical and vehicular engineering, electronic equipment, and information technology. Access was possible, as the authors had all studied and worked at the two institutions.

The eligibility criteria included being at least 18 years old and a current student at one of the universities. We focused on undergraduate students because they are typically the main participants in Girls' Day events and are more involved in campus activities. The recruitment began during the autumn semester of 2019 and occurred through teacher recommendations and campus advertisements. A total of 16 undergraduate students agreed to participate in the study. Four male students who were responsible for the Girls' Day activities in their classes were identified via the student organisation and general office of the two universities; four other male students who had not directly participated in the festival celebrations were randomly selected from the volunteers. We also randomly recruited eight female students, inviting a total of eight female and eight male students to participate (Table 1). 
Table 1: Characteristics of study participants $(N=16)$

\begin{tabular}{|l|l|l|}
\hline Student Characteristics & Number & \% of Total \\
\hline Major & & \\
\hline Law & 1 & 6.25 \\
\hline History & 1 & 6.25 \\
\hline Physics & 1 & 6.25 \\
\hline Political Science & 1 & 6.25 \\
\hline Clinical Medicine & 1 & 6.25 \\
\hline Sociology & 2 & 12.5 \\
\hline Chemical Engineering & 2 & 12.5 \\
\hline Mechanical Engineering & 2 & 12.5 \\
\hline Electronic Information Science and Technology & 2 & 12.5 \\
\hline Computer Science and Technology & 3 & 18.75 \\
\hline Grade & & \\
\hline Year 1 & 2 & 12.5 \\
\hline Year 2 & 5 & 31.25 \\
\hline Year 3 & 6 & 37.5 \\
\hline Year 4 & 3 & 18.75 \\
\hline Gender & & \\
\hline Male & 8 & 50 \\
\hline Female & 8 & 50 \\
\hline & & \\
\hline
\end{tabular}

\section{Interview Procedure}

The data reported in this study were collected through semi-structured interviews with 16 undergraduate students. The 16 participants were divided into two groups, with eight participants (4 males and 4 females) in each group. Group interviews were conducted during the spring semester in 2020. Because of the COVID-19 pandemic, two rounds of focus group discussions took place via a Zoom video conference, lasting two hours each. When participants entered the Zoom meeting for the online interview, the investigator obtained informed consent and checked participants' identities, which included their age, gender identity, ethnicity, year at university, and major. Once all the participants were present, the facilitator began the group interview process using a semistructured interview guide. Semi-structured interviews allow for flexibility through the use of open-ended questions where the order of subsequent questions is determined by participants' responses (Dearnley 2005). This offers students the opportunity to discuss, confront, and negotiate meanings in reflexive and inclusive ways. Students were also encouraged to use whatever spoken language and words came naturally to them. At the request of the participants, their real names have not been published here, and English letters have been used instead (Table 2). 
Table 2: Interview groups

\begin{tabular}{|l|l|}
\hline Interviews & Participants \\
\hline Focus Group 1 & Male: A, B, C, D \\
\hline (Question-master 1) & Female: E, F, G, H \\
\hline Focus Group 2 & Male: I, J, K, L \\
\hline (Question-master 2) & Female: M, N, O, P \\
\hline
\end{tabular}

To ease the participants into the discussions, at the beginning of the interviews the participants were briefed on the focal themes and what would be included and were shown relevant text and pictures of Girls' Day banners. A sample question that was asked of all participants was, "What is your understanding of Girls' Day banners at University?" Additionally, examples of questions about Girls' Day banners and gender issues included, "Do you think these slogans constitute a gender issue?" and "Do you think this phenomenon will persist for a long time? Under what conditions might it change?"

After completing the interviews, the online interview video was transcribed verbatim by the research team. For the transcription process, the listen-and-type method was used (Hackman et al. 2017). A member of the research team watched the video recording and transcribed the audio verbatim. To determine the accuracy of the transcription, the final transcripts were cross-checked by another member of the team. Each interview was coded using the thematic analysis as outlined by Braun and Clarke (2006). Throughout the research, we used two-people-code technology; the two authors conducted the coding process. The investigators utilised line-by-line coding for all interview data. The intercoder reliability was found to be between 0.91 and 1.00 . Since the mutual trust between the coders was quite high, formal coding began after the coder's reliability was verified.

\section{Results}

The analysis resulted in the identification of four predominant themes related to Girls' Day banners. These themes are analysed in the text below.

\section{"Aren't We Expressing Our Support and Help for Women?"}

Nearly half the interviewed male college students were not conscious of the issues highlighted by the questions. They participated in the planning and arrangements for Girls' Day, but did not consciously consider the gender issues behind the event. They believed that the banners offering "help to finish homework" conveyed caring about female students.

Participant A, a male student, was the monitor and main individual responsible for two consecutive years of Girls' Day activities planning. He admitted that he had seen banners on campus that included phrases such as "help with homework" and had once 
also intended to make a banner with a similar theme, but his classmates had felt that it would make the girls happier to praise them for their beauty and youth.

Researcher 1: What do you think about these slogans that portray male students as role models who provide girls with help and support for their academic problems?

A: I think these slogans can well express the connotation of Girls' Day. Nowadays, Girls' Day is celebrated with boys putting up banners for celebration. We want to design it as a day on which boys can express their care for or praise of girls.

Researcher 1: Do you think this will make the girls feel happy?

A: Yes. You are a girl. Today is Girls' Day, and we will spoil you today. After seeing boys put up banners for them, the girls will feel very happy and gain a superior sensethe girls would think that the boys in our class are celebrating Girls' Day for us, and all the other students on campus have seen it.

Meanwhile, $\mathrm{C}$ described his feelings regarding participation in Girls' Day activities with the word "downhearted".

C: We wrote these slogans with goodwill. But after we put them up on Girls' Day, we found that some people criticised us, saying that "helping girls write code" was actually insulting to female students. I felt very aggrieved. As everyone knows, homework for engineering students, such as writing code and experiment reports, takes a long time to finish and a lot of effort. That is why we proposed that boys would write the code. Our original intention was to show our gentlemanly side.

Student L said he was willing to participate in the interview because he was curious about why some netizens (users of the internet) viewed their carefully prepared slogans for the Girls' Festival as gender discrimination. He queried, “Aren't we expressing support and help for women?"

From these students, we can see that with the publicity and participation of the media outside the college, Girls' Day has become increasingly influential, and various innovative ways have emerged to celebrate the day. Every year, tourists flock to see the Girls' Day banners that are displayed across campuses, with photos or articles generating many comments online. Male students also face increasing pressure, whether from the school or their classmates, and they all give significant thought to holding an impressive celebration on this day. However, for those male students who are preparing for Girls' Day, their intention with hanging banners with these slogans was to convey kindness rather than discrimination towards or dissatisfaction with female students. Nevertheless, media publicity, along with a great deal of caviling, has forced students to be particularly careful about how they display praise and concern for female classmates. 


\section{"Thanks to These Gentle Boys"}

More than half the female respondents explicitly opposed linking Girls' Day slogans to gender stereotypes and IQ bias. From their perspective, male students were sacrificing their time to provide special care to women, and this should not be faulted, but appreciated.

Researcher 1: Is there any gender discrimination in the Girls' Day slogans on campus?

E: As a lucky girl, I never felt it. I think it is a form of emotional expression and praise from male students to female students, containing in-depth friendship and blessings.

Researcher 1: Can words that describe helping female students to finish their homework be viewed as a kind of goodwill?

E: It can be expressed this way. Even if boys write about helping us do experiments or write code, it does not mean that they would do what they say. As far as I am concerned, the boys are simply expressing their kind-heartedness and care for us. Those who view such care as a kind of gender discrimination are too sensitive in mind. Discrimination is moral denunciation, so it is improper for us to describe kind-heartedness as discrimination.

Another female student, $\mathrm{O}$, supported this view, adding:

The content of these slogans is not the focus at all: What is important is that it is an opportunity for deep communication between male and female students, and a romantic expression of friendship, collective spirit, and a sense of belonging among classmates. It is a precious memory for our girls at University $\mathrm{T}$. The festive wishes are designed to show boys' care for girls. How can it be taken as a kind of discrimination? This shows how boys in this University attempt to treat girls gently. If girls are so sensitive to these slogans, they might then take many words and behaviours in their daily lives as discrimination.

Student G shared a similar view:

When I read medieval literature as a child, I admired the chivalry of respecting women. Aren't these boys in our school the same? March Seventh Girls' Day shows the boys' respect for girls. Boys have been working tirelessly to roll out red banners with kind words and loving phrases. It is undoubtedly the most romantic day on campus. Also, boys took the initiative to reach out to girls who might need help, which should not be seen as gender bias but rather as a manifestation of gentlemanly demeanour, and we should not criticise them but rather thank these gentle boys.

At the end of our discussion, the female students reflected on the connotations of "care":

G: I think the care expressed through the slogans should not be equated to a kind of discrimination or that you are weaker than me. That boys help girls with their homework 
does not mean that girls have difficulty in learning engineering subjects, such as writing code. Girls can perform equally excellently at STEM subjects as boys do, and sometimes even outperform them.

H: I agree. Girls' Day is a chance for the boys to take care of and spoil girls. But this does not mean that girls are weak, so they need care from boys.

Researcher 1: So, do you mean that spoiling is not kindness shown by the strong for the weak and that spoiling can also mean respect?

H: Not necessarily respect. It can mean "attention".

G: I think it means "sincerity".

Researcher 1: So, you care about whether you have gained adequate attention and whether boys treat you sincerely.

G: Yes, I think so.

In summary, these female students recognise the male students' behaviour as expressing "care" and "kindness" to female students through the campus festival. Specifically, they clarify that "care" might not necessarily include "discrimination". The interview results demonstrate that Girls' Day is just one of the many activities created by students to enliven the campus atmosphere. However, the gender and rights relations behind this highly gender-based festival have not drawn the full attention of most students.

\section{"True Words May Not Be Beautiful, But They Are the Truth"}

Some of the male interviewees were able to understand and identify the gender metaphor behind the slogans, but informed us frankly, using concrete examples, that this is not a form of discrimination, but a fact of university campus life.

Student I proactively told us that boys provide academic assistance to female students in STEM majors because female students do have difficulty with these subjects. J, a friend of I, provided more detailed information:

Researcher 2: So, do you think this phenomenon is related to the banners from March Seventh Girls' Day?

J: Of course. As a campus cultural activity, different departments will design different slogans according to their subject characteristics. "To help with writing code" in STEM subjects reflects the real situation among computer or engineering majors. Do you know how almost all the famous computer scientists are men? Girls have difficulty learning these subjects, and often ask the boys for help, although true words never sound pleasant.

$\mathrm{K}$ : I come from an engineering institute, and this is quite a common phenomenon in our department. Some girls, even if they achieve good grades in their majors, seem to have 
to make greater efforts than the boys do. That is one potential reason for the appearance of such banners. In response to this phenomenon, male students volunteer to help female students write code.

Researcher 2: So, you agree with the argument that "girls cannot learn engineering subjects well?"

$\mathrm{K}$ : To be frank, it is true. The characteristics of engineering subjects, such as the need for rigorous mathematical and logical thinking, are not suitable for girls, and we all know that women scientists account for a small proportion of the overall field. My supervisor, a well-known professor in STEM fields, has complained privately more than once that he does not want to recruit female graduate students again because their scientific research performance demonstrates that they have difficulty completing the assigned tasks, while the tutor has to pay a scholarship, which is a bad "deal". Thus, I cannot find a better explanation except that women are not naturally fit to study science and engineering.

In summary, some boys think that girls are not good at STEM subjects, and therefore require academic help. For them, banners that display messages such as "help write code" are a reflection of the real situation.

\section{"Stop. I Don't Need Discrimination Disguised as Care"}

Despite the tendency of students to feel puzzled by claims of discrimination or to express understanding for the messages displayed on Girls' Day banners, there were some who protested against the campus banners. Some students felt that the slogans were "excessive" and disrespectful to women, whereas other students adopted a feminist stance and resolutely expressed their dissatisfaction and indignation. However, in terms of what leads to this phenomenon and who needs to take primary responsibility for the popularity of this type of campus culture, there was a stark contrast between male and female students.

P: Girls' Day slogans sound attractive, with words such as "fairy", "goddess", "princess", or "queen". Boys seem to be girls' slaves, sending us roses, loving us for life, and serving us with their labour. It seems that we gain everything and pay nothing. What is the purpose of hanging these things that flatter women? Such care has taken girls as a special group at school. Is this really the case? The special treatment created for Girls' Day is without doubt discrimination against females. "Today is Girls' Day, let us be kind to them." Such kindness lasts for a single day. What we need is not help but respect and equality.

Student $\mathrm{N}$ stated that women are considered intellectually inferior and that this bias exists not only in social groups but also in a space that should be more rational and equitable: "This phenomenon makes me quite agitated. It is even packaged as a gift for girls in these banners. Stop. I don't need discrimination disguised as care." 
F and M are both from the Sociology and Humanities Department. They are more familiar with gender research. They expressed their opinions from the perspective of gender theories:

F: It appears to be a selfless act to help female students, but it is actually a sugar-coated lie. The whole slogan presupposes that, as a girl, you are not clever enough and simply cannot finish academic tasks on your own, so you need to seek boys' support. When surrounded by such a campus culture for a long time, I am deeply worried that girls will gradually acquiesce to the idea that they are born into the "weaker" sex and take it for granted that male students are more intelligent than them.

Student M adopted the same position:

International Working Women's Day [8 March] calls for people to respect women instead of speaking superficially. The most important thing is that it teaches people to remember those people who fought, shed blood, and made sacrifices for females to be considered equal and take the name of "women". But, in the campus context of March Seventh Girls' Day, it has undergone various changes. For example, we are talking about slogans like "help girls do homework and write code", where there is a long-standing stereotype of women, who are rarely represented in many areas considered to require high intelligence, especially science and technology. An originally anti-bias, antidiscrimination festival has been alienated into a school culture that supports prejudice and discrimination.

Male interviewee B acknowledged this bias and discrimination in the slogans, but believed that the main responsibility for the formation of this culture lies with the female college students, not the men who wrote them:

B: I have never been concerned about the origin of this unofficial festival, although there is March Seventh Girls' Day every year in my university. After agreeing to accept this visit, I checked the information about how the International Women's Day on 8 March, also known as International Working Women's Day in China, has made important contributions and achieved a great deal concerning the celebration of women in economic, political, and social fields. College girls replaced this with the March Seventh Girls' Day, promoting the "youthful vitality" of girls' features, refusing to be labelled as working women or to admit that they are adult women. So, does this mean that female college students are afraid to assume the social responsibility of adult women? Since they lack the basic social responsibility of a socially independent individual, they cannot blame others for labelling them as "not smart enough", "not capable", and so on.

F: I agree. I think it is absurd that contemporary society and college students so widely misinterpret and distort the significance of the commemoration of Women's Day on 8 March. Women's Day commemorates Chicago women's labour struggles for equal rights in pay, divorce, and abortion, rather than letting you consume gender symbols, and some foolish women even think they are enjoying a gender dividend. 
The respondents thought that care should not indicate the weakness of a group. The bias against females concerning their performance in STEM subjects might be spread through such campus festivals. Many slogans on Girls' Day, apart from reflecting the love between men and women, use words such as "fashion", "beauty", "queen", "dream girl", "gentleness", and "virtuousness". Some activities even propose "different kinds of help for girls". These slogans stem from a lack of awareness of the social construction of gender. We also observed that students who have a clear gender perspective and basic knowledge of women's issues are more sensitive towards the gender connotations underlying these college slogans.

\section{Discussion}

\section{Continued Gender Inequality}

Considering the changes in gender culture and the educational level of women, it is evident that the emergence of Girls' Day in contemporary Chinese colleges and universities is by no means accidental. It has not only benefited from the increase in the number of female college students (Girls' Day would be impossible as a large-scale campus cultural event if the number of female college students was very small), but is also deeply influenced by the change in gender concepts in contemporary China. The main conclusion is that Girls' Day reflects the gender perspectives of young students on university campuses. Behind the slogans, a "benevolent sexism" conceptualises female college students as weak, incompetent, and in need of protection. The current March Seventh Girls' Day, which is in full swing on Chinese university campuses, is not conducive to gender equality. Despite the increased representation of women in Chinese universities, the numerical female advantage at the undergraduate level does not fundamentally change the unequal gender rights relations between men and women. In the traditionally male-dominated STEM departments this situation is even more serious.

At a surface level, Girls' Day is a day to care for college female students. However, based on the results of the interviews, the March Seventh Girls' Day is dominated by male students and has gradually morphed into a campus culture that supports prejudice and discrimination. Its banners create the impression that male students should treat females unconditionally well; females should be taken care of, and females need males' help to complete school. These ideas deepen gender differences and create the stereotype that females should enjoy the care and love of males. Glick and Fiske (1996) have put forward the concept of "benevolent sexism" to describe the phenomenon whereby men adopt a protector-and-provider role towards women. From this perspective, a man may hold two beliefs about women that he views as entirely consistent with each other, which are "Women are incompetent at work" and "Women must be protected". This position actually combines notions of the exploited group's lack of competence to exercise structural power with self-serving "benevolent" justifications ("We must bear the burden of taking care of them") that allow members of the dominant group to view their actions as not being exploitative. Regarding the relationship between men and women constructed through the banners, the question 
arises whether women are simply the objects of men's fun or can be admired and respected as equals by men in this context. The banners ostensibly demonstrate care for women, but in a way that reinforces gender stereotypes between men and women in the name of caring.

The pursuit of lively campus festivals is not, in itself, inappropriate; however, in the long run, it is likely to go to extremes, creating overly rigid gender divisions. Although some girls have put out the banner, "What we need is not free lunch, but to be respected and treated equally", it is generally difficult to alter the potential discrimination. Girls' Day as a festival in which men show their love for women has led to a deepening of college students' inherent prejudices on gender in subtle ways, such as the belief that men should help disadvantaged women, and women are valuable only when they are loved by men. Women still experience patriarchy and hegemonic masculinity, which manifest in various forms of discrimination. Moreover, when rigid cultural gender roles are strong and gender equality mainstreaming is slow or absent, a higher number of female students does not translate into a decrease in gender-based bias, stereotyping, and violence (Nesterova and Jackson 2018).

As Hung and Tzeng (2018) found in a study of a team-based engineering course, girls "naturally" get help from boys in the name of "care" in teamwork because they are influenced by the belief that the learning ability of girls in engineering is lower than that of boys. In our interviews, female IQ bias based on gender stereotyping appeared to be a long-standing issue, which has been subconsciously inherited across generations of Chinese college students. The proportion of boys and girls who lack gender awareness is high; they are used to acquiescing to this tradition and are more willing to affirm one another, constantly defending this prejudice and emphasising the rationality of its existence, rather than engaging with and questioning it by independent reflection. "Females' IQs are not as high as males' IQs" has become the collective gender consciousness, showing gender bias and reflecting the asymmetric power relationship between men and women, even among higher education students. In the absence of Girls' Day as a platform for expression, this may only be a popular private view among students; however, in recent years, with the influence of these banners that are actively displayed on campus, it has been amplified in the public space, becoming an increasingly powerful, open voice.

The view that female college students are in need of males' help is reflected in the fact that although women are included in the university education system based on the requirement that their talents be trained, it remains difficult for them to enter the practical field of scientific research and social service independently. Encouraging male students to help female students through banner slogans takes gender difference as its premise and replaces "equal rights" with "female privilege", which also truly reflects the roles of men and women in the school culture. A woman's sense of shame about her lack of intelligence, pointing to the double negation by herself and the external collectivity, leads her to become the "other" at the university (derived from the Latin 
Universitas Magistrorum et Scholarium, which generally translates to "the community of teachers and scholars").

\section{The Return of Traditional Gender Concepts}

According to the official website of Tsinghua University, Girls' Day is a festival that "defines youth, vigor, an independent and confident attitude to life for all girls and it also shows men's respect towards women and also the equality of men and women" (Tsinghua University News 2019). One senior official of the Student Administration Office interviewed for this study considered Girls' Day to be a symbol of harmonious relationships between girls and boys. He even told us that "[n]ow you cannot really tell that there are gender discrimination problems in this beautiful campus."

According to our research, the sponsor of Tsinghua University's Girls' Day was an outstanding woman named Song Qiang, who enrolled in the university's Department of Thermal Engineering in 1989. At that time, the ratio of men to women at Tsinghua was approximately 6:1. Some departments and classes had no female students and there were only two female students in Song Qiang's undergraduate class of 27 people. Song Qiang was enthusiastic about public welfare and, in her senior year, became the vice-chairman of the school's student union responsible for the welfare of female students on campus. In 1993, Tsinghua girls, in Song Qiang's view, had a limited understanding of society due to the lack of communication channels. At that time, society still held the traditional belief that women should be industrious wives and mothers rather than develop their careers. For various reasons, Song and the school's directors decided to launch a "Girls' Day" to allow female students to further consider their social roles and enable all students to improve and cultivate their learning abilities. However, the current situation demonstrates that Girls' Day is no longer a festival for female college students to improve and express themselves, and the banner festival of Girls' Day is shifting further and further from its original intention to highlight women's professional abilities and independent character.

In our interviews, several male and female students noted the difference between March Seventh Girls' Day and International Women's Day. The latter was established in memory of the Women's Liberation Movement and women suffering from brutal oppression; in this sense, self-confidence and independence are the true spiritual core of the festival. However, the popularity of March Seventh Girls' Day reflects the fact that Chinese female college students believe that International Women's Day is a festival for married women rather than "girls", who are younger and more energetic than older women; therefore, to distinguish themselves, yet maintain their unique female festival, they selected the day before International Women's Day as their unofficial Girls' Day, which gradually developed into a festival for men to offer benefits and blessings to women.

Traditional male hierarchies are the norm in China; with the establishment of patriarchy, the traditional Confucian concept that men are superior to women has taken shape. It is 
commonly thought that women need to be supported by men. A woman is to be a submissive daughter, wife, and mother, who limits her speech, dresses pleasingly, and manages her household (Yuan and Cheng 2009). The return of traditional gender concepts under the Confucian influence is a phenomenon of special interest to highly educated people. Although the contemporary social mood and ideas about gender have become increasingly prominent, gender inequality persists in tertiary education.

Although some students were aware of the issues underlying this kind of "protective care" and expressed clear opposition to it, there were also students who identified with or even supported this bias. At the same time, the interview results revealed that most students' gender awareness was vague and confused. The concepts of equality, privilege, physical strength, and intelligence were often conflated, directly indicating that they did not know the exact definition and basic boundaries of gender justice. For example, very few students noticed that praising girls for their "needs, special caring and warmth" could be considered an equally egregious stereotype as girls possessing a "low IQ". All the respondents were attending top-level academic education institutions in China, but both the male and female students relied mainly on the internet or friends to obtain knowledge and news on gender issues, and the information provided by society was confusing or even incorrect. This is a typical side effect of the lack of gender education in Chinese colleges and universities, which, at present, can only be spontaneously and individually explored by students. It also reflects the general inadequacy of equal rights and gender education in Chinese university campuses (Zhao et al. 2020), where the challenges related to gender inequality did not simply go away, and where female students still face a difficult situation.

\section{Conclusions}

Our interviews demonstrated that college students are oblivious to gender issues in campus culture and manifest low gender consciousness, which is in line with previous findings (Zhao et al. 2020). In terms of the IQ bias on campus banners, only a few of the interviewees had ever considered the following questions: What is the object of feminist criticism? What kinds of behaviour and discourse are violations of women's legitimate rights and interests? In which areas do women need equal treatment and to be given special attention? What exactly do we need to fight and protect to achieve gender equality? What behaviours and ideas are reasonable, and what initiatives could lead to a "women-centred" paradigm of opposition that places the focus of social reform on demands for more privileges for women?

Gendered education on these topics should be developed to help inform students and change the campus culture surrounding gender stereotyping and prejudice. Researchers have pointed out the necessity of including the topics of gender equity in Chinese tertiary teaching practice (Zhao et al. 2020). They also suggest that faculty and administration should guide the students to formally and informally talk about gender concepts and gender issues to enhance the understanding of gender fair and gender affirmative practices (Herring and Marken 2008). Changing the campus gender culture 
will likely require efforts at several levels; schools should take Girls' Day as an opportunity to provide students with gender education. Meanwhile, teachers should dispel gender misconceptions and guide the students on the occasion of Girls' Day festivals. The aim should be to encourage women to have equal and independent personalities and to raise society's awareness of women, rather than solidifying the stereotype of women in an environment marked by "caring for girls". College students, both male and female, should be helped to establish correct gender concepts and awareness and, thereafter, construct an anti-discrimination and anti-bias gender culture on campus. Although the long-term object of feminism is to dismantle patriarchal society, the results of our interviews demonstrated that female college students, as the backbone of the future social development, are vulnerable to the influence and impact of traditional gender culture and various values during their period of social transition, and Girls' Day activities have encouraged and magnified this mentality. Therefore, educating female college students about gender justice should be one of the goals of higher education. Both men and women need to make changes and accept criticism. In the interviews, we also discovered that male students do not seem to profit directly from this gender inequality. However, to achieve the desired image of a bright, strong, gentle male, college students devote a great deal of time and energy to helping female students complete the school's various examinations. If they do not reflect on their gender roles, and why they are left with this impression by the culture of Girls' Day, they will not understand why the common conception of the "more intelligent male" is a genderrelated issue caused by patriarchal prejudices, and consequently, like their "less intelligent" female classmates, they will fall into the patriarchal trap. To this end, male students need to take the initiative to change or break through the shackles of traditional gender culture. Appropriate university gender education would help to reverse gender stereotypes and IQ bias in the campus culture, and, in the long term, can be an effective way for women and men to fully develop their potential.

This study has some limitations. Given that the qualitative data were derived from a limited sample size of voluntary participants, the applicability and generalisability of the results may be limited. The findings of this study are suggestive rather than definitive. Additionally, this study was undertaken at two well-known universities in China, and the participants were all students who had participated in the activities of March Seventh Girls' Day. Whether the same or a similar campus culture can be found at other mainland Chinese colleges and universities that do not celebrate Girls' Day, and the gender problems reflected by it, should be further explored deeply and comprehensively.

\section{References}

Braun, V., and V. Clarke. 2006. "Using Thematic Analysis in Psychology". Qualitative Research in Psychology 3 (2): 77-101. https://doi.org/10.1191/1478088706qp063oa. 
Breen, R., R. Luijkx, W. Müller, and R. Pollak. 2009. "Nonpersistent Inequality in Educational Attainment: Evidence from Eight European Countries". American Journal of Sociology 114 (5) :1475-521. https://doi.org/10.1086/595951.

Cralley, E. L., and J. B. Ruscher. 2005. "Lady, Girl, Female, or Woman: Sexism and Cognitive Busyness Predict Use of Gender-Biased Nouns". Journal of Language and Social Psychology 24 (3): 300-14. https://doi.org/10.1177/0261927X05278391.

Dearnley, C. 2005. "A Reflection on the Use of Semi-Structured Interviews". Nurse Researcher 13 (1): 19-28. https://doi.org/10.7748/nr2005.07.13.1.19.c5997.

Deary, I. J., S. Strand, P. Smith, and C. Fernandes. 2007. "Intelligence and Educational Achievement”. Intelligence 35 (1): 13-12. https://doi.org/10.1016/j.intell.2006.02.001.

Forgasz, H. J., G. C. Leder, and P. Kloosterman. 2004. "New Perspectives on the Gender Stereotyping of Mathematics". Mathematical Thinking and Learning 6 (4): 389-420. https://doi.org/10.1207/s15327833mt10604_2.

Glick, P., and S. T. Fiske. 1996. "The Ambivalent Sexism Inventory: Differentiating Hostile and Benevolent Sexism". Journal of Personality and Social Psychology 70 (3): 491-512. https://doi.org/10.1037/0022-3514.70.3.491.

Guangming Daily. 2013. “Warm Girls’ Day”. Accessed July 29, 2021. http://epaper.gmw.cn/gmrb/html/2013-03/23/nw.D110000gmrb_20130323_5-10.htm.

Gurin, P. 1985. “Women's Gender Consciousness”. Public Opinion Quarterly 49 (2): 143-63. https://doi.org/10.1086/268911.

Hackman, C. L., S. E. Pember, A. H. Wilkerson, W. Burton, and S. L. Usdan. 2017. "SlutShaming and Victim-Blaming: A Qualitative Investigation of Undergraduate Students' Perceptions of Sexual Violence”. Sex Education 17 (6): 697-711. https://doi.org/10.1080/14681811.2017.1362332.

Herring, S. C., and J. A. Marken. 2008. "Implications of Gender Consciousness for Students in Information Technology”. Women's Studies 37 (3): 229-56. https://doi.org/10.1080/00497870801917150.

Hung, J.-H., and J.-Y. Tzeng. 2018. "Promoting Gender-Inclusion or Reproducing MaleDominance? From Female Perspectives on Project-Based Learning in Engineering Study". Bulletin of Educational Research 64 (2): 43-83. https://doi.org/10.3966/102887082018066402002.

Kollmayer, M., B. Schober, and C. Spiel. 2018. "Gender Stereotypes in Education: Development, Consequences, and Interventions". European Journal of Development Psychology 15 (4): 361-77. https://doi.org/10.1080/17405629.2016.1193483. 
Nesterova, Y., and L. Jackson. 2018. “Gender Inequality in Universities”. Impakter, November 2, 2018. Accessed December 15, 2020. https://impakter.com/gender-inequalityuniversities/.

Parker, M., and K. L. Davis. 1999. "Giving Women a Chance to Learn: Gender Equity Principles for HPERD Classes”. Journal of Physical Education, Recreation and Dance 70 (4): 13-15. https://doi.org/10.1080/07303084.1999.10605905.

Rainey, A. B., and J. O. Rust. 1999. "Reducing Gender Stereotyping in Kindergartners". Early Child Development and Care 150 (1): 33-42. https://doi.org/10.1080/0300443991500103.

Rinehart, S. T. 2013. Gender Consciousness and Politics. New York, NY: Routledge. https://doi.org/10.4324/9781315866482.

Sohu News. 2020a. "Banner Collection of Tsinghua Girls' Day that Moved the Whole". Accessed on July 29, 2021. https://www.sohu.com/a/378437974_641792.

Sohu News. 2020b. "Selection of Girls' Day Banners at Shanghai Jiao Tong University during Quarantine”. Accessed on July 29, 2021. https://www.sohu.com/a/378275189_657731.

Tsinghua University News. 2019. “Girls’ Day Celebrated”. Accessed December 15, 2020. https://news.tsinghua.edu.cn/en/info/1021/1878.htm.

UNESCO (United Nations Educational, Scientific and Cultural Organization). 2016.

"Education and Gender Equality". Accessed July 29, 2021.

https://en.unesco.org/themes/education-and-gender-equality.

Xinhua News Agency. 2017. "Women Dominate Higher Education in China”. Accessed July 29, 2021. http://www.xinhuanet.com/english/2017-10/27/c_136710572.htm.

Yuan, H., and L. Cheng. 2009. Berkshire Encyclopedia of China: Modern and Historic Views of the World's Newest and Oldest Global Power. Great Barrington, MA: Berkshire Publishing.

Zhang, W. 2021. "China's Female Students Want to Abolish Girls' Day”. Sixth Tone, March 8, 2021. Accessed July 29, 2021. https://www.sixthtone.com/news/1006929/chinas-femalestudents-want-to-abolish-girls-day.

Zhao, P., L. Yang, Z. Sa, and X. Wang. 2020. "Propriety, Empowerment and Compromise: Challenges in Addressing Gender among Sex Educators in China". Sex Education 20 (5): 552-67. https://doi.org/10.1080/14681811.2019.1705779. 